\title{
AS LUTAS E FILOSOFIAS DE NELSON MANDELA E A PROPOSTA HABERMASIANA DA AÇÃO COMUNICATIVA
}

Rafaela Carqueijeiro Moro, Wagner Augusto de Labio Orlando

Centro Universitário Eurípides de Marília - UNIVEM, Curso de Direito. E-mail: rafaela.cm96@gmail.com, wagnerdelabio@hotmail.com

\section{RESUMO}

O artigo aqui desenvolvido e apresentado pretende, de maneira sucinta, demonstrar uma ligação entre a vida de Mandela e suas lutas e filosofias, bem como apresentar a estrutura da teoria habermasiana como solução de conflitos de forma pacífica, pela razão/ação comunicativa, sobretudo no que se refere ao entendimento e compreensão intersubjetivos. Abordamos a luta de Mandela em vieses variados, introduzindo a filosofia do direito, a bioética e até mesmo biopolítica de forma sutil, com a intenção de despertar a consciência não só filosófica, mas dar uma demonstração empírica de que, apesar de todas as dificuldades e o então cenário de segregação no qual Mandela estava inserido, a violência não é o melhor caminho a se adotar para se alcançar a paz social.

Palavras-Chave: Fraternidade; Igualdade; Liberdade; Democracia; Razão Comunicativa.

\section{THE FIGHTS OF NELSON MANDELA AND THE HABERMASIAN PROPOSAL OF COMMUNICATIVE ACTION}

\begin{abstract}
The article here developed and presented aims, in a succinct way, to show an interconnection between the life of Mandela and his fights and philosophies, as well as present the habermasian theory structure as a conflict resolution in a pacific way, by the communicative reason/action, overall in the intersubjective understanding and comprehension. We connect Mandela's fights in various biases, introducing the philosophy of Law, bioethics and even biopolithics in a soft way, with the aim to grow the not only philosophical consciousness, but give an empirical demonstration that, even though all difficulties and the scenario in which Mandela was inserted, violence is not the best way to achieve social peace.
\end{abstract}

Keywords: Fraternity; Equality, Freedom, Democracy; Communicative Reason. 


\section{INTRODUÇÃO}

A fraternidade como categoria constitucional, em sua própria essência, como ressalta Ricardo Hasson Sayeg, está na sociedade como "uma vinculação constitucional à antropofilia, isto é, uma sociedade que supera o antropocentrismo e descola o homem do entro do universo para o meio das coisas, estabelecendo, entre todos e tudo uma conexão universal" (SAYEG, 2011, p.101); em Maritain, com um pouco mais de complexidade, apresenta-se em um âmbito mais subjetivo mas não menos importante -, que parte do indivíduo em sua mais profunda benevolência.

Estamos frente a um debate em que, analisando as particularidades da filosofia de Nelson Mandela, cogitamos a existência de uma interligação com a filosofia do direito. Nela, especialmente no que se trata da relação interpessoal, colocamos um viés prático, estudando a fundo a vida e lutas de Mandela, bem como aquilo que concordamos fazer parte de uma construção de saberes voltada ao respeito, liberdade e fraternidade.

\section{METODOLOGIA}

A metodologia compõe-se, basicamente, em uma profunda análise bibliográfica, sobretudo das obras de Jürgen Habermas e as que tratam da vida e obra de Nelson Mandela, onde pudemos encontrar discussões fundamentais à compreensão ligada aos objetos de estudo deste artigo, atrelados e inseridos no mundo da vida, de forma que se fizesse a interligação com dados empíricos, sobretudo no que tange o cenário e período do Apartheid, definindo um raciocínio delineado pela fraternidade e igualdade, passando pelas teorias da comunicação de Habermas, chegando, assim, a um resultado mais claro e preciso.

No que se refere aos objetos de estudo, pretendemos apresentá-lo ao leitor de forma a instigar, estimular e incentivar o pensamento crítico e conscientizador. Os resultados consistem, da mesma forma, no desfecho das análises do campo teórico e empírico, apresentando os desdobramentos dos objetos no mundo da vida, bem como propostas de solução - principalmente no que se refere à ação comunicativa.

\section{RESULTADOS}

Realizados os estudos e análises bibliográficos, considerando os pressupostos já pertinentes em uma análise - como pudemos apresentar - de uma forma um tanto quanto histórica, ressaltamos que, dentre os estudos, a maior constatação foi a interligação das filosofias de Nelson Mandela com a obra habermasiana, sustentando e reforçando ainda mais a proposta da razão comunicativa.

Estivemos frente a um debate bastante complexo, havendo a dificuldade em resumir todo o contexto em poucas páginas. No entanto, pudemos ressaltar a essência da luta pacífica e a intenção de reforçar a ideia da compreensão e respeito à intersubjetividade. Estabelecendo os paralelos fundamentais para a devida compreensão, encontramos uma seleção de ideais que, em conjunto, apresentam a síntese do que pretendemos passar.

\section{DISCUSSÃO}

Rolihlahla Mandela nasceu em 18 de julho de 1918 em uma aldeia chamada Mvezo, em Trnskei. O nome Nelson foi dado aos seus sete anos por um professor. Já com vinte e um anos, matriculou-se na Universidade de Fort Hare, em Alice, de onde foi expulso por participar de protestos, evidenciando, desde cedo, sua vontade de mudar o cenário em que vivia. Mudou-se para Johannesburgo em 1941 para escapar de um casamento arranjado; foi este o momento onde sua luta pela discriminação racial na África do Sul tem seu início. (Mandela, 2010, p. 384).

A primeira organização política dos negros sul-africanos foi o Congresso Nacional Africano, fundado em 1912, com objetivo de combater a segregação e as injustiças existentes no país, inicialmente de forma pacífica, mas, posteriormente, mais radical, a partir de uma violenta 
repressão a uma manifestação em Sharpeville (Pereira, 2010, p. 47 - 49). Mandela inicia sua jornada contra injustiças raciais justamente por meio do CNA, tendo, em 1952, sido eleito presidente do Congresso da província do Transvaal e automaticamente vice-presidente da CNA (Mandela, 2010, p. 384 e 385). Desde então, a luta no Apartheid fez parte da vida de Mandela, assim como as perseguições e prisões; a primeira delas ocorreu logo no primeiro ano em que havia se tornado vice-presidente do Congresso Nacional Africado, condenado pela Lei de Repressão ao Comunismo. Foi preso e acusado de traição.

Novamente livre, já em 1960, ocorre o episódio conhecido como Massacre de Sharpeville; como consequência, o governo sul-africano decreta a ilegalidade do CNA, do Congresso Panafricanismo e do Partido Comunista. A luta de Mandela muda, então, da diplomacia para uma resistência armada e ele passa, inclusive, por treinamento militar para reunir apoio para o CNA. Foi em 1963, porém, que viria a ser o episódio conhecido como Julgamento de Rivonia, episódio mais conhecido e, talvez, mais impactante na vida e filosofia de Mandela. Neste episódio, ocorrido em junho de 1964, foi dada a ele a sentença de prisão perpétua, tenho sido Mandela levado para a Ilha de Robben, onde cumpriria grande parte de sua pena (Mandela, 2010, p. 385 e 386). Mandela recusou, neste período, duas ofertas para ser libertado. Após 26 anos preso, e após o CNA ser retirado da ilegalidade, Mandela é libertado em 11 de fevereiro de 1990, um ano depois é eleito presidente na primeira conferência nacional do Congresso Nacional Africano na África do Sul. Recebe em 1993, junto com o presidente F.W. de Klerk o Prêmio Nobel da Paz e no ano seguinte, é eleito presidente da África do Sul, logo em sua primeira eleição democrática e após cumprir seu mandato, não se candidata a reeleição e em 2004, aos 86 anos, Madiba - como também é conhecido - anuncia que está deixando a vida pública (Mandela, 2010, p. 387).

Tendo em vista o histórico de vida de Mandela, vemos evidenciada sua luta em busca da liberdade, igualdade e da fraternidade. Primeiramente, é necessário enfatizar que apesar de terem conceitos e aplicações diferentes, a liberdade e a igualdade caminham juntas, ou ao menos, para se ter uma sociedade justa, a igualdade deveria estar lado a lado com a liberdade dos indivíduos. Norberto Bobbio, ensina que:

o conceito e o valor da igualdade pressupõem, para sua aplicação, a presença de uma pluralidade de entes, cabendo estabelecer que tipo de relações existe entre eles: enquanto se pode dizer, no limite, que é possível existir uma sociedade na qual só um é livre (o déspota), não teria sentido afirmar que existe uma sociedade na qual só um é igual. (1997, p.13)

Trazendo este conceito para a realidade do Apartheid, o déspota seria a camada branca do país sul-africano, os seres livres, enquanto que a maioria da população do país - os negros - era desprovida de liberdade. Isso faz com que exista uma sociedade na qual somente alguns são iguais. Madiba - como também era chamado - buscava não só a liberdade para seu povo, mas também igualdade de condições, de oportunidades, de locomoção, e como meio para alcançar este ideal, utilizava-se da fraternidade, de se evitar ao máximo o conflito e a violência, buscando o fim da segregação racial baseada no diálogo.

É aí, portanto, que fazemos uma ligação com a obra do filósofo e sociólogo alemão Jürgen Habermas, no que se refere à teoria da razão/ação comunicativa. Tomando a razão comunicativa no "âmbito de uma teoria reconstrutiva", como expõe o próprio Habermas (2003, p.21), devemos entendê-la como uma conexão entre indivíduos, de forma que estes, em uma comunicação e seguindo alguns pressupostos, abrem-se à compreensão de argumentos e opiniões, tendo uma discussão honesta e não tão-somente individualista, como observamos tanto no Apartheid, como nos dias atuais. Assim, tendo os indivíduos como fontes e destinatários de uma determinada ação/norma, há, indispensavelmente, a necessidade de que haja um consenso entre os indivíduos e a possibilidade de uma discussão racional e aberta ao entendimento de uma forma pacífica, 
como defendia Mandela em sua filosofia. Isto posto, pode nos remeter novamente à questão da racionalidade. A representatividade, dentro de uma dita democracia, necessitando de ordenação linguística dos cidadãos e, nesta, a utilização exclusiva da razão, nos leva a crer que a maneira a se estabilizar as expectativas de comportamento da sociedade, apesar das estruturas complexas e diferentes entre si pode estar contida no direito moderno, resultante da racionalização e ligado à integração social (HABERMAS, 2003, p. 105).

A efetiva representatividade seria atingida a partir do momento em que o instrumentalismo integrador do direito se pusesse como elo entre o indivíduo e o Estado, compondo um mecanismo de se expressar a vontade social, porém, ainda mais importante e anterior a isso, deveríamos, em nossas relações interpessoais, tomar por base a racionalidade como fator de legitimidade dos discursos intersubjetivos, a fim a estabelecer ou formular uma objetividade, resultando num consenso. Habermas, em síntese, assim apresenta:

"O conceito de agir comunicativo, que leva em conta o entendimento linguístico, como mecanismo de coordenação da ação, faz com que as suposições contrafactuais, dos atores que orientam seu agir por pretensões de validade adquiriram relevância imediata para a construção e manutenção de ordens sociais: pois estas mantém-se no modo de reconhecimento de pretensões de validade normativas. Isso significa que a tensão entre facticidade e validade, embutida na linguagem e no uso da linguagem, retorna ao modo de integração de indivíduos socializados comunicativamente - devendo ser trabalhado pelos participantes. Essa tensão é estabilizada de modo peculiar na integração social realizada por intermédio do direito positivo" (2003, p.35)

A luta pela fraternidade entre os povos é evidente na jornada de Mandela, ele buscava a todo tempo, evitar uma guerra civil, ou qualquer ato que colocasse as raças em conflito. Exemplo claro disso, ocorreu quando Chris Hani, um dos líderes do Congresso Nacional Africano, este que também buscava o fim do Apartheid, porém com um viés mais violento, fora assassinado por um polonês, na ocasião, Madiba estava preso e fora chamado para fazer um discurso em rede nacional no lugar do presidente sul-africano:

"Esta noite, estou me dirigindo a cada sul-africano, negro ou branco, do mais profundo do meu ser. Um homem branco, cheio de preconceito e ódio, veio ao nosso país e cometeu um ato tão hediondo que nossa nação inteira agora oscila à beira do desastre. Uma mulher branca, de origem bôer, arriscou sua vida para que pudéssemos conhecer este assassino e fazer justiça. O frio assassinato de Chris Hani chocou todo o país e o mundo. Nosso pesar e raiva estão nos consumindo. O que aconteceu é uma tragédia nacional que tocou milhões de pessoas além da divisão política e de cor.

Terminou desta forma:

"Este é um divisor de águas para todos nós. Nossas decisões e ações irão determinar se usaremos nossa dor, nosso pesar e o ultraje para caminharmos em direção à única solução duradoura para o nosso país um governo eleito pelo povo, do povo e para o povo." (Stengel, 2010, p. 29).

Fica evidente sua preocupação com a possível eclosão de uma guerra civil. Aproveita-se do fato de ter sido uma mulher branca quem ajudou a identificar o culpado e a enaltece numa 
tentativa de passar uma mensagem pacificadora para toda a população da África do Sul. A cirurgia na próstata a qual Mandela foi submetido após mais de 20 anos preso foi a grande reviravolta na luta contra o Apartheid; houve uma mudança radical na postura de resistência. Depois da cirurgia, fora colocado em uma cela isolada, em um andar diferente de seus companheiros e aliados políticos; foi a oportunidade para Mandela colocar em prática uma ideia que há anos vinha planejando, que ao ponto de vista da CNA seria considerado uma heresia - iria iniciar conversas com o governo do país, coisa que o seu partido não fazia há muito tempo.

Esta seria a segunda tentativa de um contato com o governo - o primeiro foi quando o presidente $\mathrm{P}$. W. Botha propusera a liberdade de Mandela caso este renunciasse a violência como instrumento político e obteve a seguinte resposta de Mandela: "Somente homens livres podem negociar. Prisioneiros não podem apresentar contratos. Não posso e não vou dar nenhuma garantia, em uma época na qual eu e você, o povo, não somos livres. A sua liberdade e a minha não podem ser separadas". (Stengel, 2010, p.36). Agora uma nova abordagem e novas negociações com o presidente Botha, culminariam em resultados que levariam não apenas a sua libertação, mas também às primeiras eleições democráticas da história da África do Sul (Stengel, 2010, p.36).

Porém sua luta não iria acabar por aí; Mandela precisava ainda estruturar a recente democracia, fortalecê-la e por isso se candidatou a presidência. Mais uma vez mostra sua preocupação, tanto com a população negra, quanto com a população branca de seu país, pois em campanha dizia que para os negros ele seria seu defensor e para os brancos, que seria seu protetor. O resultado foi a vitória de Mandela e a promulgação de Constituição democrática.

Neste fundo há que se estabelecer nos direitos humanos - este, como elo e inerente ao indivíduo - a base de uma democracia e inserir a ela a autodeterminação, conectando a essência do direito ao Estado democrático de direitos (HABERMAS, 2003, p. 128-129). Tendo em vista, no cenário do Apartheid, a dispersão da ideia de justa soberania entre as esferas públicas, deparamonos mais uma vez com a ideia suscitada por Habermas da teoria do discurso, a se orientar na tomada de decisões e administração das instituições do Estado de direitos (DURÃO, 2009, p. 119).

Assim, podemos identificar a importância da teoria no cenário segregacional, carente de democracia, garantindo que a fundamentação dos direitos, portanto, seria possível pela teoria do discurso, uma vez que, segundo Habermas:

"Partimos da história dos dogmas do direito subjetivo, a fim de mostrar como a legitimidade surge paradoxalmente da legalidade; desenvolvemos, a seguir, um modo próprio de interpretar o conceito de autonomia, na linha de uma teoria do discurso, o qual torna possível reconhecer o nexo interno entre direitos humanos e soberania do povo. Pesquisamos, finalmente, a relação complementar entre direito e moral, a fim de esclarecer a determinação formal que permite distinguir entre normas jurídicas e normas gerais da ação" (2003, p. 155).

\section{CONCLUSÃO}

Ao final de nosso estudo, pudemos constatar ainda mais a importância da comunicação adequada e a racionalização das discussões, com o intuito de entendimento e compreensão plenos. Estivemos engajados em um debate em que, pelo exemplo de Mandela, figura fundamental na luta contra a segregação racial, sobretudo no Apartheid, tendo em vista a teoria da comunicação fundada na pacificidade e na fraternidade.

Ao abrirmos a discussão adentrando os aspectos da vida de Mandela, encontramos uma maneira de apresentar e estudar suas lutas e aqueles pontos essenciais à construção de uma filosofia e de saberes voltados à resolução pacífica e fraternal de conflitos. A isso, podemos dizer 
que encontramos um paralelo com aquilo que Habermas chama de ação comunicativa, onde como já posto -, a compreensão e racionalização dos conflitos é fundamental.

Estando frente a uma luta que mudou uma sociedade completamente, pudemos compreender melhor o Apartheid e suas políticas, motivações e razões da derrocada. Desta forma, almejamos ofertar um exemplo de sucesso na luta pacífica contra as mazelas, tendo em vista o esforço não só de Mandela, mas de um grupo que não se conformou ou se intimidou com a política segregacional; muito pelo contrário, houve a motivação sustentada pelo absurdo dessas políticas, das mentalidades nada sãs que estimularam o sistema. Neste cenário, a mudança de perspectivas de Mandela - da luta armada à pacífica - em muito se assemelha ao que pudemos observar, por exemplo, no Brasil em 2013, onde, de manifestações e enfrentamentos turbulentos nas ruas, houve gestos que se tornaram símbolos, com grande apelo para a não violência. Em um grande paralelo com o Apartheid e a luta pela igualdade, recentemente observamos os gestos semelhantes no episódio de Baton Rouge, onde negros ainda manifestam-se contra a violência de policiais; a jovem de aspecto sereno defronte a policiais causou mais impacto que muitos tiros.

Desta forma, como abordamos na teoria da comunicação de Habermas, observamos a interligação fundamental, uma vez que, neste viés, o filósofo defende a proposta da razão comunicativa, que, por sua vez, propõe-se a assegurar a subjetividade dos indivíduos envolvidos em dissenso, inclusive segregacional, de forma que estes alcancem o consenso através da intersubjetividade mediada pela razão, em contrapartida à razão estratégica, na qual já há definidos os fins.

A dignidade humana, em sua forma mais essencial, está intimamente ligada ao trabalho em questão; temos que, de forma a apresentar o pensamento filosófico correlacionado ao período do Apartheid e sua derrocada, achamos por bem sopesar as variações sociais desde então, para, desta forma, melhor compreender das influências que pretendemos sugerir ao cenário jusfilosófico brasileiro.

\section{REFERÊNCIAS}

MANDELA, Nelson. Conversas que tive comigo. Trad.: Ângela Lobo de Andrade, Nivaldo Montingelli Jr. e Ana Deiró. Rio de Janeiro: ROCCO, 2010.

PEREIRA, Analúcia Danilevicz. A África do Sul Independente: Segregação, Apartheid e Transição Pactuada (1910-1994). In Africa do Sul, História, Estado e Sociedade. Org. VISENTINI, Paulo G. Fagundes e PEREIRA, Analúcia Danilevicz. Brasília: Fundação Alexandre de Gusmão, 2010. Disponível em: <http://funag.gov.br/loja/download/709-africa do Sul Historia Estado e Sociedade.pdf > Acessado em 05/07/2016.

BOBBIO, Norberto. Igualdade e Liberdade. Trad.: Coutinho, C. N. Rio de Janeiro: Ediouro, 1997.

STENGEL, Richard. Os Caminhos de Mandela: Lições de Vida, Amor e Coragem. Trad.: Douglas Kim. São Paulo: Globo, 2010.

HABERMAS, Jürgen. Direito e Democracia: Entre facticidade e validade. Vol I Trad.: Flávio Beno Siebeneichler. Rio de Janeiro: Tempo Brasileiro, 2003.

DURÃO, A. Barbieri. A tensão interna entre facticidade e validade no direito segundo Habermas. Orgs.: MARTINS, Clélia Aparecida e POKER, José G. A. B.. O pensamento de Habermas em questão. Marília: Oficina Universitária Unesp, 2008. 